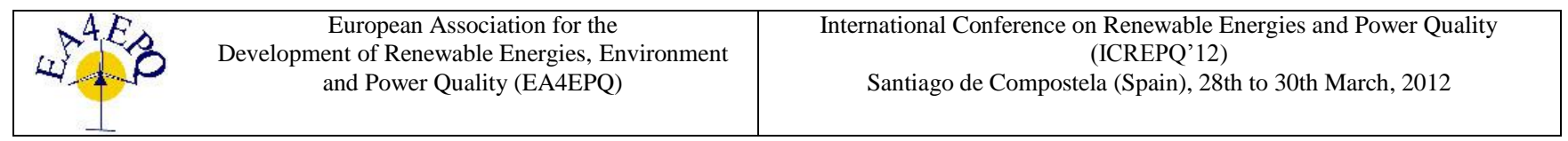

\title{
A Computational Contribution in order to Study Cogeneration Power Plants
}

\author{
F. A. M. Moura ${ }^{1}$, J. R. Camacho², G. C. Guimarães ${ }^{2}$ and M. L. R. Chaves ${ }^{2}$
}

${ }^{1}$ Department of Electrical Engineering

UFTM, Universidade Federal do Triângulo Mineiro

ICTE - Av. Dr. Randolfo Borges Júnior, 1250 Uberaba (Brazil)

Phone/Fax number:+55 (34) 3318-5600, e-mail: fabricio@eletrica.uftm.edu.br

${ }^{2}$ Department of Electrical Engineering

UFU, Universidade Federal de Uberlândia

Campus Santa Mônica - João Naves de Ávila, 2121 Uberlândia (Brazil)

Phone/Fax number: +55 (34) 3239-4734, e-mail: ircamacho@ufu.br, gcaixetag@yahoo.com.br, lynce@ufu.br

\begin{abstract}
The deregulation of the energy matrix, as evidenced in several countries, together with the need to have renewable energy sources in the system, contributes to the widespread installation of energy auto-producers in the electrical system. However, a number of factors, not less important, as the instability in energy prices, high costs of expansion of conventional electricity generation, the emerging of new environmental policies and incentive to the use of renewable sources such as the Program for the Incentive of Alternative Energy Sources - PROINFA in Brazil resulted in the promotion and the increase in the number of generating units from sugarcane plants interconnected to the mains. Nevertheless, a series of technical operating issues, in order to ensure the excellence of the mains power, and system integrity, concerns the independent producer and the larger network when analyzing the parallelism through contingency situations.
\end{abstract}

\section{Key words}

Distributed generation, synchronous generator, voltage profile, voltage regulator, speed governor, TACS, cogeneration.

\section{Introduction}

Considerable efforts have been developed to encourage the installation of independent electricity producers in distribution systems. Obvious example of such efforts is demonstrated by the attempt to standardize their interconnection and protection requirements [1]. However, this standardization can be difficult due to variations in the design of distribution circuits, the various types of generators coupled to the network and the particular requirements of each utility. However, a series of questions points to the development of further studies to ensure the quality of electric power, the system transient stabilty and lifetime of the blades of steam turbines.
Distributed generation shows frequent use of steam turbines as a primary machine to produce electricity. Such units have increased considerably due to a restructuring of the energy sector worldwide.

Most of the process of converting thermal energy into electrical energy occurs in the steam turbine. This is due to the numerous advantages of such turbines over other similar technologies. Among the main advantages stands the balanced construction, relatively high efficiency, few moving parts, ease of maintenance, and availability in large sizes. The industries that typically employ the technology of cogeneration are the sugar and alcohol, the pulp and paper and oil refining.

Recently, special attention has been spent to turboalternators under abnormal conditions of operation of the electrical system concerning the frequency (over or under frequency). In particular, major research efforts have been spent with the main aim of assessing the possible damage they are subjected to the steam turbine when in operation under conditions of prolonged under frequency, during a severe overload condition imposed on the system when occurring a deficit of generation.

Contingencies common to the distribution of electricity systems can cause serious damage to the generators installed in parallel to the network as well as steam turbines responsible for providing mechanical power to their axis. Thus, it is necessary to assess the possible impacts of steam turbines of the IP (independent producer) electrical machinery in system abnormal operating conditions. For this it is essential to develop a computer model able to represent accurately the phenomena experienced. 


\section{System Modeling}

\section{A. Voltage Regulator}

A synchronous generator is used to represent the independent power producer; it is the type SM 59 with eight controls in the ATP model databank [2]. The voltage regulator is based in one of the models that are the basis for excitation regulators [3], [4] and [5].

According to the data input, this model can be reduced to four basic forms. The model used in this work for the voltage regulator can be seen in Figure 1, it is the type I model, one of the most complete designs recommended by the IEEE.

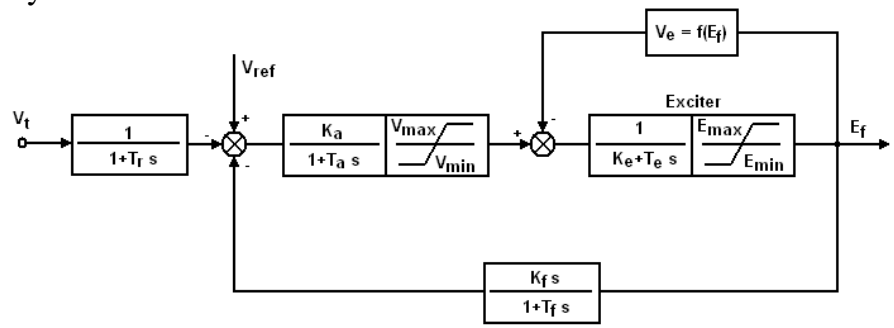

Fig. 1. Voltage regulator model.

\section{B. Speed Regulator}

The speed regulator was implemented based in one of the simplest IEEE models, and often used in transient stability studies programs.

Figure 2 presents the block diagram for the speed regulator associated to the steam turbine (if $\mathrm{T}_{4}=0$ ) or to the hydro turbine (if $\mathrm{T}_{4} \neq 0$ ).

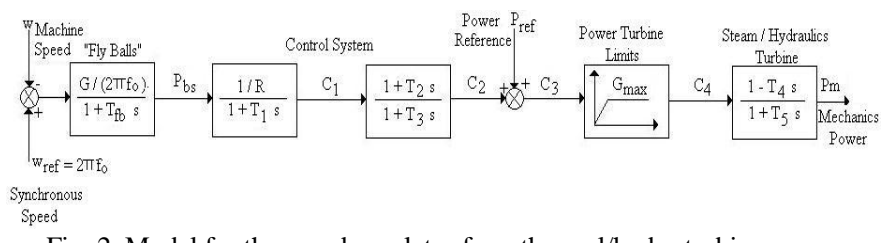

Fig. 2. Model for the speed regulator for a thermal/hydro turbine.

\section{Electrical System}

The independent power producer generators become part of the electrical system of a power authority distribution network, as illustrated in Figure 3. Such system is connected to the independent power producer through an interconnecting circuit breaker, following instructions established in [6]. Data depicted in Figure 3 refer to the system rated values, however, particularly for the independent power producer generator does not operate with a 0.8 lagging power factor, after performing a load flow.

The source type representing the power authority was defined as a three-phase ideal source, being considered, therefore, as an infinite bus bar. To use such controllable model in ATP, it will be necessary to define the data listed in Table I.

The rated parameters obtained for the machine voltage and speed regulators, as well as data referred to the independent power producer synchronous generator, were obtained directly from manufacturers.

Table I - Synchronous machines parameters for the independent generator

\begin{tabular}{|c|c|c|}
\hline \multicolumn{3}{|c|}{ Data need for $\mathrm{G} 1(\mathrm{G} 1=\mathrm{G} 2)$} \\
\hline $\mathrm{S}_{\mathrm{n}}=5 \mathrm{MVA}$ & $\mathrm{R}_{\mathrm{A}}=0.004 \mathrm{pu}$ & $\mathrm{x}_{\mathrm{d}}=1.8 \mathrm{pu}$ \\
\hline $\mathrm{U}_{\mathrm{n}}=6.6 \mathrm{kV}$ & $\mathrm{x}_{\mathrm{L}}=0.1 \mathrm{pu}$ & $\mathrm{x}_{\mathrm{q}}=1.793 \mathrm{pu}$ \\
\hline $\mathrm{x}_{\mathrm{d}}{ }_{\mathrm{d}}=0.166 \mathrm{pu}$ & $\mathrm{x}_{\mathrm{q}}{ }_{\mathrm{q}}=0.98 \mathrm{pu}$ & $\mathrm{x}{ }_{\mathrm{d}}=0.119 \mathrm{pu}$ \\
\hline $\mathrm{x}{ }_{\mathrm{q}}=0.17 \mathrm{pu}$ & $\mathrm{x}_{0}=0.046 \mathrm{pu}$ & $\mathrm{T}{ }_{\mathrm{d} 0}=1.754 \mathrm{~s}$ \\
\hline $\mathrm{T}_{\mathrm{q} 0}=0 \mathrm{~s}$ & $\mathrm{~T}{ }_{\mathrm{d} 0}=0.019 \mathrm{~s}$ & $\mathrm{~T}{ }_{\mathrm{q} 0}=0.164 \mathrm{~s}$ \\
\hline $\mathrm{H}_{\mathrm{l}}=1 \mathrm{~s} ; \mathrm{H}_{2}=2 \mathrm{~s}$ & $\mathrm{P}=4 \mathrm{poles}$ & $\mathrm{f}=60 \mathrm{~Hz}$ \\
\hline
\end{tabular}

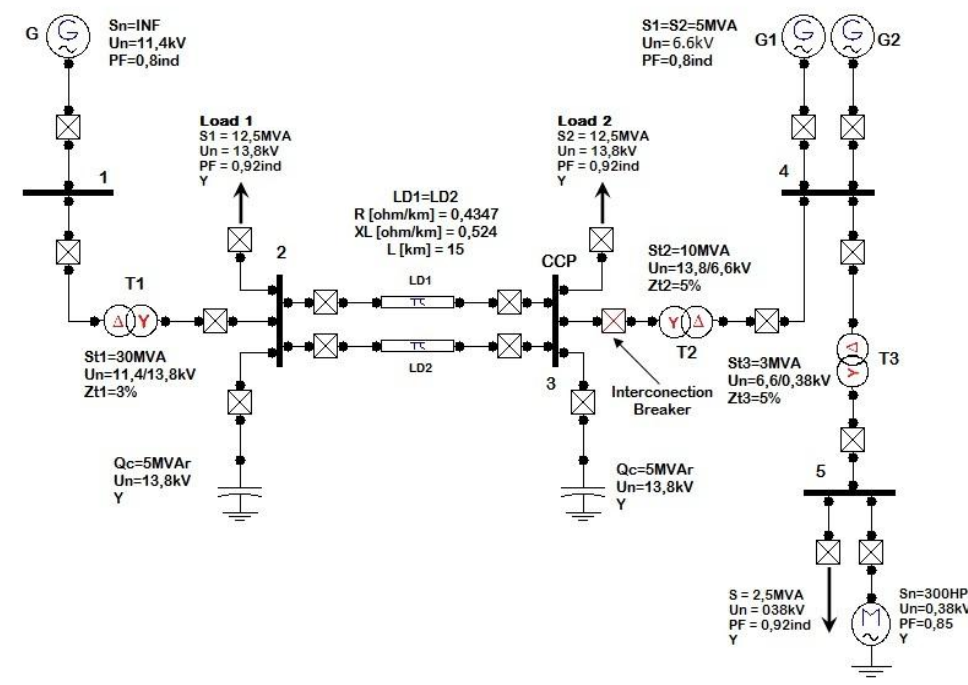

Fig. 3. Single line diagram for the electrical system in the case considered

\section{Power Flow}

The energy independent generation provides a total power of 4 MVA to the interconnection with the power authority electrical system, through the coupling transformer, $\mathrm{T} 2$.

Furthermore, the independent power producer provides energy to its internal demand, rated in 2.8 MVA.

Active and reactive power produced by the Independent Power Producer (G1 and G2) can be seen in Table II.

Table II - Active and reactive power generated by the independent power producer by phase

\begin{tabular}{|c|c|c|}
\hline Source & $\mathrm{P}_{\mathrm{G}}[\mathrm{MW}]$ & $\mathrm{Q}_{\mathrm{G}}[\mathrm{MVAR}]$ \\
\hline $\mathrm{G} 1=\mathrm{G} 2$ & 0.7 & 0.25 \\
\hline
\end{tabular}

Before the presentation of the studied cases, it is necessary to highlight that depending upon the "penetration", for the distributed generation, the obtained results will be affected differently. Similar works using others software and using the Alternative Transients Program - ATP, were developed by [7] and [8]. 


\section{Nomenclature}

$V_{t}$ - voltage at the independent generator bus bar $(\mathrm{pu})$,

$V_{\text {ref }}$ - reference voltage (pu),

$K_{a}$ - regulator gain,

$K_{e}$ - exciter constant related to self-excited field,

$K_{f}$ - time gain for the regulator stabilizer circuit,

$T_{a}$ - regulator amplified time constant (s),

$T_{r}$ - regulator input filter time constant,

$T_{e}$ - exciter time constant,

$T_{f}$ - time constant for the regulator stabilizer circuit (s),

$E_{\max }$ - maximum exciter output voltage (applied to generator field),

$E_{\text {min }}$ - minimum exciter output voltage (applied to generator field),

$V_{e}=f\left(E_{f}\right)$ - saturation function,

$V_{\max }$ - maximum limit for the regulator output voltage (pu),

$V_{\min }$ - minimum limit for the regulator output voltage (pu),

$E_{f}$ - field voltage (pu),

$S_{n}$ - rated aparent power,

$U_{n}$ - rated voltage,

$L$ - lenght,

$R_{A}$ - armature resistance (pu),

$x_{L}$ - armature leakage reactance $(\mathrm{pu})$,

$x_{d}$ - direct axis reactance $(\mathrm{pu})$,

$x_{q}$ - quadrature axis reactance $(\mathrm{pu})$,

$x_{d}^{\prime}$ - direct axis transient reactance $(\mathrm{pu})$,

$x_{q}^{\prime}$ - quadrature axis transient reactance $(\mathrm{pu})$,

$x_{d}^{\prime \prime}$ - direct axis sub transient reactance (pu),

$x_{q}{ }_{q}$ - quadrature axis sub transient reactance (pu),

$x_{0}$ - zero sequence reactance $(\mathrm{pu})$,

$T_{d \mathbf{0}}$ - direct axis transient short-circuit time constant (s),

$T_{q 0}^{\prime}$ - quadrature axis transient short-circuit time constant (s),

$T_{d_{0}}^{\prime \prime}$ - direct axis sub transient short-circuit time constant (s),

$T_{q 0}^{\prime}$ - quadrature axis sub transient short-circuit time constant (s),

$H$ - inertia moment (s),

$P$ - pole number,

$f$ - frequency $(\mathrm{Hz})$,

$\omega_{s}$ - synchronous speed ( $\left.\mathrm{rad} / \mathrm{s}\right)$.

\section{Case Studies}

\section{1- Sudden opening of the interconnection breaker}

It is worth clarifying to the reader the pre-established conditions to the speed governors of the IPP machines, these where adjusted to operate with a $5 \%$ slope, in order to better meet the interconnection [4]. Therefore, no machine installed in the IPP generation, has the characteristic to ensure that frequency oscillations will be inside the favorable frequency range, i.e., there is no need for the presence of an isochronous generator.

Faced by the sudden opening of the interconnection circuit breaker there is a considerable fluctuation in the speed of the electric machine G2, Figure 4. Such transient oscillation immediately affects the frequency in the electrical system belonging to the IPP, burdening strongly the quality of electricity, especially with regard to the efficiency of micro-computerized devices [9].

However, slight changes in the operating speed of the machines originate variations in power demand, since the active and reactive powers, required by electrical loads vary dynamically with system frequency. Nevertheless, there is clearly and strongly the tendency of the synchronous machine speed G2 to stabilize, as shown in Figure 4 in the period after contingency, thus indicating the influence of the IPP generation penetration in the transient stability of its own machines.

As for the speed regulator, Figure 5 convincingly portrays the attempt of that regulator to meet the new situation imposed on the system.

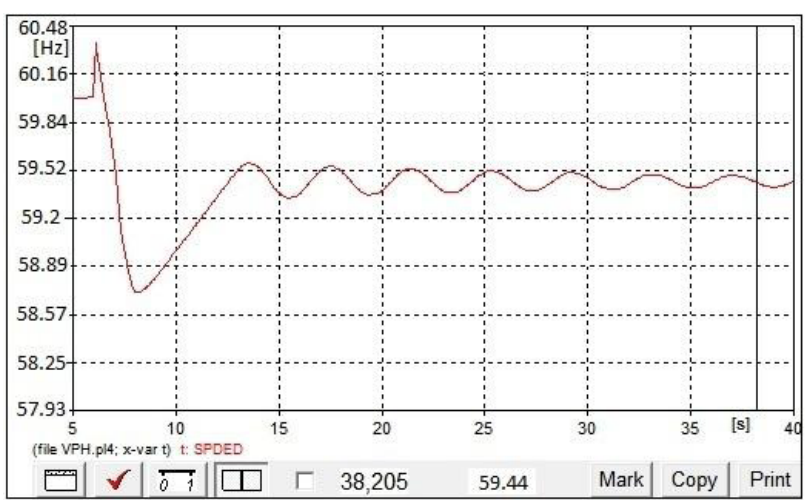

Fig. 4. Operating frequency

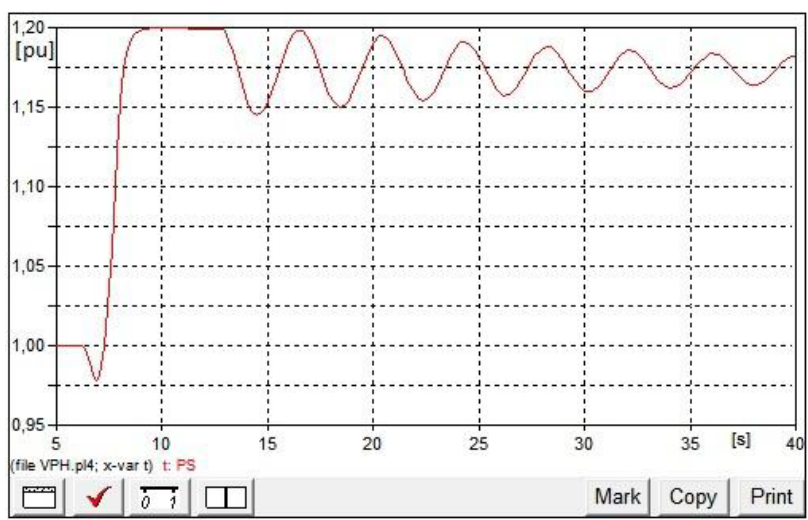

Fig. 5. Action of speed governor

In the moment immediately after the opening of the interconnection breaker, the machine is subjected to an immediate rejection of load. Thus, the operating speed rises gently to $189.63 \mathrm{rad} / \mathrm{s}(\mathrm{f}=60.4 \mathrm{~Hz}$ ). However, at this moment the lower inertia machine $\mathrm{G} 1$ is taken out of 
the system, in order to restore the load-generation balance.

It is worth mentioning the performance of the machine G2 speed regulator in Figure 5 to reduce the steam consumption to ensure the $\mathrm{G} 2$ synchronous speed.

With the withdrawal of G1, a new scenario is presented with respect to the Power flow in the system. The machine G2 becomes responsible for all the electrical loads at the IPP. Thus, according to equation (1), the balancing equation, the electrical power becomes greater than the mechanical power, which leads to deceleration of the generator, taking the angular speed to $\omega=184.45$ $\mathrm{rad} / \mathrm{s}(\mathrm{f}=58.71 \mathrm{~Hz})$. At this moment, the speed governor acts to increase the steam consumption to restore the load-generation balance. However, the frequency of operation of the machine oscillates in a damped transient between $\mathrm{f} 1=59.6 \mathrm{~Hz}(\omega=187.15 \mathrm{rad} / \mathrm{s})$ and $\mathrm{f} 2=59.33$ $\mathrm{Hz}(\omega=186.42 \mathrm{rad} / \mathrm{s})$, and tends to stabilize at a frequency $\mathrm{f}=59.4 \mathrm{~Hz}$, i.e., $\omega=186.74 \mathrm{rad} / \mathrm{s}$.

$$
\frac{2 \cdot H \cdot d^{2} \delta}{\omega_{R} \cdot d t^{2}}=P_{m}-P_{e}=P_{a}
$$

As for the speed governor, it follows the oscillations observed in the operating speed of the machine G2, tending to stabilize around $1.17 \mathrm{pu}$, in other words, it is necessary the production by the boilers of $17 \%$ more steam, to be supplied to the generators turbine to meet the new request of active power, as can be observed in Figure 5.

The moment immediately after the withdrawal of the machine $\mathrm{G} 1$, the remaining generator $\mathrm{G} 2$ reaches the frequency $\mathrm{f}=58.71 \mathrm{~Hz}$. That is classified as extreme, burdening sharply the impeller blades of this generating set. However, during the damped transient period, G2 oscillates within the tolerable region of Table III. The observation of such limits ensures the life time of the equipment, thus reducing the mechanical wear of turbine blades and reduces the number of stoppages for maintenance of this generating set.

Table 3 - Characteristic zones of frequency for operation of

\begin{tabular}{|c|c|}
\hline \multicolumn{2}{|c}{ turbines } \\
\hline OPERATION ZONE & FREQUENCY $-\mathrm{f}(\mathrm{Hz})$ \\
\hline Favorable & $\mathrm{fn}-0,17 \%<\mathrm{fn}<\mathrm{fn}+0,17 \%$ \\
\hline Tolerable & $\mathrm{fn}-1 \%<\mathrm{fn}<\mathrm{fn}+1 \%$ \\
\hline Extreme & $\mathrm{fn}-6 \%<\mathrm{fn}<\mathrm{fn}+1,7 \%$ \\
\hline
\end{tabular}

In order to get a better response in operation for the IPP electrical system after the opening of the interconnection circuit breaker, it is possible the insertion of a flywheel in the axis of $\mathrm{G} 2$, in order to rise the generating set equivalent inertia. However, it is necessary to reject the generating unit G1 inside the $100 \mathrm{~ms}$ after the application of contingency.

The flywheel is a mechanical device with significant moment of inertia used for storing rotational energy. Has high resistance to variations in speed, which helps to ensure a small variation in rotation speed of the shaft.
It is presented here different situations for three specific inertia moments, and their corresponding implications on the speed response of the IPP generator G2 in Figures 6, 7 and 8.

With the increase in the synchronous machine G2 equivalent moment of inertia, due to the insertion of a wheel, in Figure 6 for $\mathrm{I}=600 \mathrm{kgm}^{2}$, there is the stabilization of the operating speed of the generator for the considered time period in the simulation at $\mathrm{t}=40 \mathrm{~s}$.

However, at the moment immediately after the untimely opening of the interconnection breaker, the operating speed of machine $\mathrm{G} 2$ reaches $\omega=189.5 \mathrm{rad} / \mathrm{s}$ ( $\mathrm{f}=60.3$ $\mathrm{Hz}$ ). This is due to the instantaneous rejection of the applied load. Nevertheless, due to the withdrawal of machine $\mathrm{G} 1, \mathrm{G} 2$ provides a considerable reduction in its speed of operation due to the increase in electric power demand. The frequency reduces to $184.93 \mathrm{rad} / \mathrm{s}$ ( $\mathrm{f}=58.9$ $\mathrm{Hz}$ ), the extreme region of operation according Table 3. However, the machine varies in speed within the range between $\quad 186.53<\omega<187.07 \mathrm{rad} / \mathrm{s}, \quad$ or $59.4<f<59.5 \mathrm{~Hz}$. Note that, observing Table III, the oscillation frequency remains within the favorable zone of operation, ensuring the life time of steam turbine blades [4].

Figure 7 shows the response to an equivalent moment of inertia $\mathrm{I}=700 \mathrm{kgm}^{2}$. The system has more damping, reducing the time required to reach a new steady state speed at $\omega=186.77 \mathrm{rad} / \mathrm{s}(\mathrm{f}=59.5 \mathrm{~Hz})$. Therefore, according Table III, the industrial frequency falls in the tolerable operating zone, contributing not only to maintain the transient stability of the system, but also ensures the integrity of the steam turbine blades, as well as presenting a significant contribution in terms of the quality of electric power [9]. As for the oscillations of frequency in the transient period, it is verified a maximum speed of $\omega=189.4 \mathrm{rad} / \mathrm{s}(\mathrm{f}=60.3 \mathrm{~Hz})$, at the moment immediately after the contingency. Nevertheless, with the removal from operation of G1, machine G2 reaches a minimum speed of $\omega=185.28 \mathrm{rad} / \mathrm{s}(\mathrm{f}=59.0$ $\mathrm{Hz})$ at the extreme operation zone.

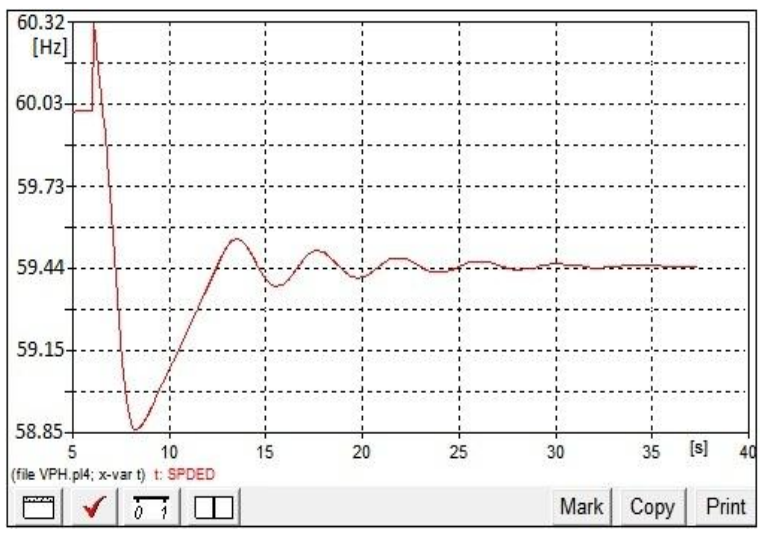

Fig. 6. Frequency response of machine G2 for I $=600 \mathrm{kgm} 2$ 


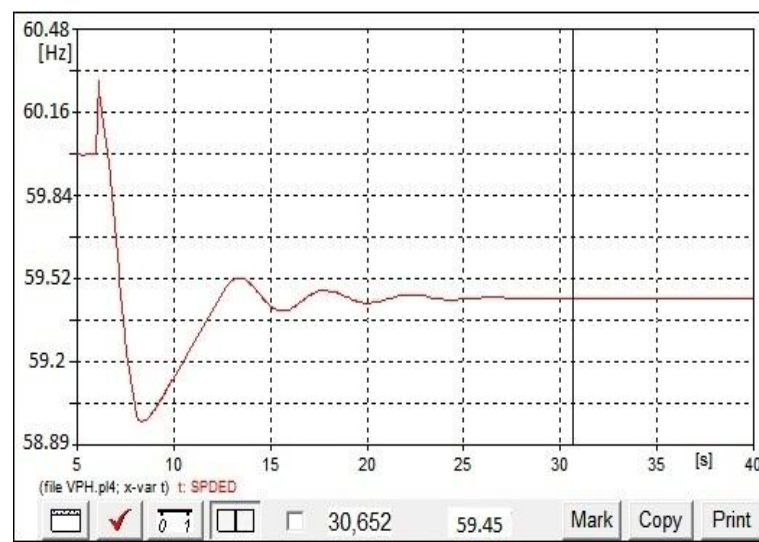

Fig. 7. Frequency response of machine $\mathrm{G} 2$ for $\mathrm{I}=700 \mathrm{kgm} 2$

However, the machine G2 varies in speed within the range between $186.61<\omega<187.01 \mathrm{rad} / \mathrm{s}$ or $59.4<f<59.5 \mathrm{~Hz}$. It can be noticed that the frequency oscillation, according Table III, remains in the favorable zone of operation, ensuring the expected life time for blades of the steam turbine.

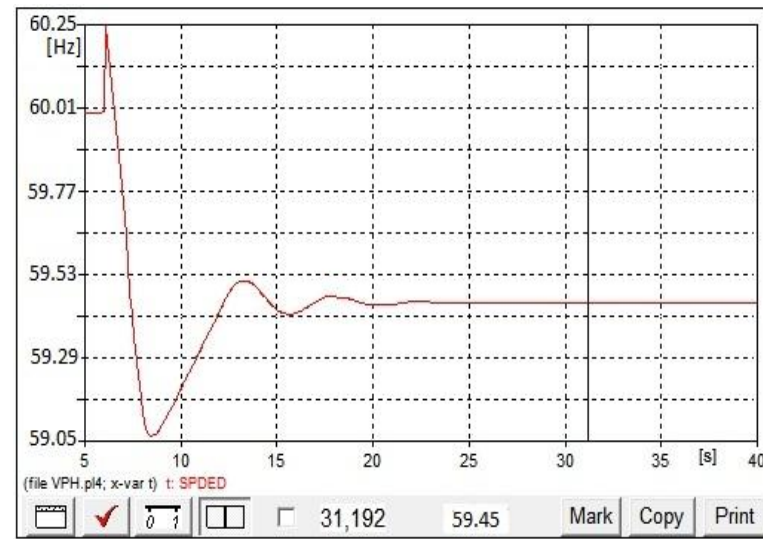

Fig. 8. Frequency response of machine G2 for $\mathrm{I}=800 \mathrm{kgm} 2$

With the main objective to reduce the oscillations, evident in the speed of operation, of the remaining synchronous generator $(\mathrm{G} 2)$ it was applied an equivalent moment of inertia $\mathrm{I}=800 \mathrm{kgm}^{2}$, the result can be seen in Figure 8. There, the damping obtained allows reaching the new steady state more efficiently. This helps to mitigate the harmful effects to the quality of electric power to ensure better response of electrical parameters of the system. With regard to changes in speed, the maximum reaches the magnitude $\omega=189.3 \mathrm{rad} / \mathrm{s}$ (f = $60.3 \mathrm{~Hz}$ ) at the tolerable zone of operation, but the minimum is settled at $\omega=185.55 \mathrm{rad} / \mathrm{s}(\mathrm{f}=59.06 \mathrm{~Hz})$ at the extreme operation zone. Thus, one can conclude here and for the other equivalent inertia moments simulated that, at the instant immediately after the removal of generator G1, the synchronous machine G2 presents a significant reduction in its operating speed. In this way, it is generated a sub-frequency costly to the physical and mechanical integrity of the turbine blades, since the obtained frequency, at this instant, fits the extreme region of operation at Table III. However, oscillations in the transient period do not affect the impeller blades, as they pass inside the tolerable zone. Nevertheless, after the damped transient period, the machine reaches the new steady-state and stabilizes at a speed $\omega=186.77 \mathrm{rad} / \mathrm{s}$ (f $=59.5 \mathrm{~Hz}$ ), similar to that obtained for the case illustrated in Figure 7.

\section{Conclusion}

Through the discussions presented along this article, there is the need to make the correct and effective study of the synchronous machine speed governors, in order to have better dynamic response of the system. However, this goal is achieved from the transfer function of these governors, so it is essential to be aware of the topology of the turbine used, i.e., whether or not this is reheating. It shows that before the model transfer function, yet it is necessary to choose an appropriate software to implement the model. In this way, it can be seen that ATP, through TACS subroutines allows the correct and efficient computational modeling of both the speed governor and voltage regulator [10], [11].

The answers regarding the performance of the speed governor, for the transfer function shown here, respond faithfully and reliably to dynamical requests imposed to the electrical system under analysis. Due to untimely performance by interconnection breaker, the IPP machines face an immediate rejection of load, which burdens the system frequency, thereby compromising the integrity of turbine blades. However, it appears that even without the application of mitigation measures the system tends to stabilize. Nevertheless, the responses refer to a system such that the penetration of IPP does not take place significantly. The literature shows that higher levels of active power exported by the IPP mean larger damage to the turbines due to higher frequency oscillations [5]. Thus, the use of the flywheel is shown as an effective alternative, since it damps transient oscillations, thus contributing to ensuring the life time of the impeller blades. In short, it is extremely important the correct modeling and use of speed governors in studies relevant to the dynamic stability of power system analysis in terms of commitment to the life time of the blades of steam turbines.

\section{References}

[1] IEEE Standard for Interconnecting Distributed Resources with Electric Power Systems, IEEE Std. 1547, New York, USA, 2003.

[2] ATP-EMTP - Alternative Transients Program, accessed in the internet in 22/11/2007, http://www.emtp.org.

[3] G. C. Guimarães, Computer Methods for Transient Stability Analysis of Isolated Power Generation Systems with Special Reference to Prime Mover and Induction Motor Modelling, PhD Thesis, University of Aberdeen, 1990.

[4] P. M. Anderson and A. A. Fouad, Power System Control and Stability, vol. I. Iowa, 1977.

[5] P. Kundur Power Systems Stability and Control, McGrawHill, EPRI Power Systems Engineering Series, New York, 1994.

[6] LIPA-Long Island Power Authority, Control and Protection Requirements for Independent Power Producers, Transmission Interconnections, found at the internet in 22/11/2007, at http://tinyurl.com/33clq4. 
[7] W. Freitas, A. M. França, J. C. M. Vieira Jr., L. C. P. da Silva, "Comparative Analysis Between Synchronous and Squirrel Cage Induction Generators for Distributed Generation Applications". IEEE Trans. Power Systems, vol. 21,NO.1, FEBRUARY 2006.

[8] C. Saldaña, G. Calzolari, G. Cerecetto, "ATP modeling and field tests of the ac voltage regulator in the Palmar hydroelectric power plant", Electric Power Systems Research, Elsevier, 76 (2006), pp.681-687.

[9] R. C. Dugan, M. F. McGranaghan, S. Santese, H. W. Beaty, Electrical Power Systems Quality, McGraw-Hill, New York, 2002.

[10] F. A. M. Moura, J. R. Camacho, M. L. R. Chaves, G. C. Guimarães, "The Dynamic Interaction of Independent Power Producer Synchronous Machines Connected to a Distribution Network in ATP-EMTP”, ICEM2010 - XIX International Conference on Electrical Machines, Roma, Italia, September 2010.

[11] F. A. M. Moura, J. R. Camacho, M. L. R. Chaves, and G. C. Guimarães, "Independent Power Producer Parallel Operation Modeling in Transient Network Simulations for Interconnected Distributed Generation Studies", Electric Power Systems Research, Elsevier, (2009), doi:10.1016/j.epsr.2009.08.016 